\title{
Erratum to: Nuclear Cardiology in the Management of Patients with Heart Failure
}

\author{
Amalia Peix ${ }^{1} \cdot$ Lázaro O. Cabrera $^{1} \cdot$ Kenia Padrón ${ }^{1}$
}

Published online: 18 February 2016

(C) Springer Science+Business Media New York 2016

Erratum to: Curr Cardiovase Imaging Rep (2016) 9:1

DOI 10.1007/s12410-015-9363-8

The authors have corrected an error in Figure 6, "Practical algorithm to evaluate patients prior to cardiac resynchronization therapy with gated-SPECT MPI." In the corrected figure, under "Evaluation of scar if ischemic DCM," "NO" now points to "Consideration for CRT," and "YES" points to "Appropriate therapy."

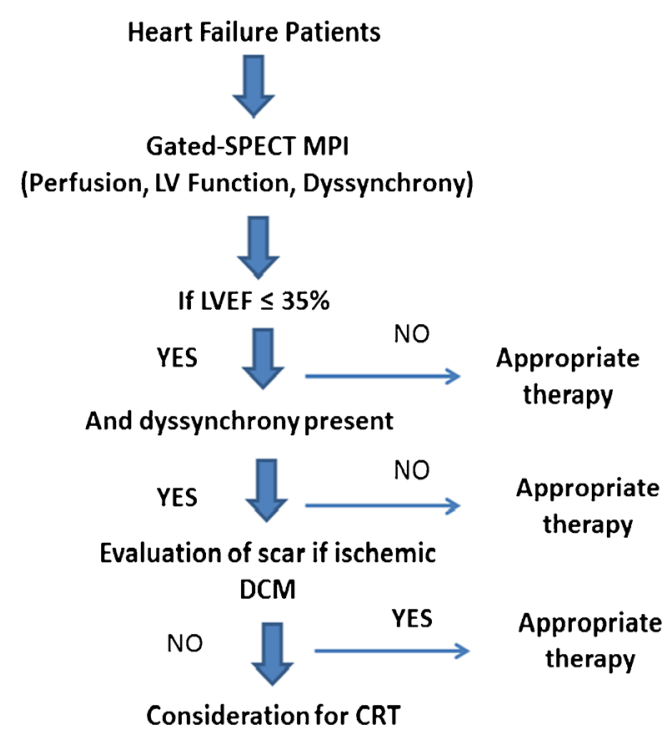

Consideration for CRT
The online version of the original article can be found at http://dx.doi.org/ $10.1007 / \mathrm{s} 12410-015-9363-8$.

\footnotetext{
Amalia Peix

peix@infomed.sld.cu

Lázaro O. Cabrera

cardiomar@infomed.sld.cu

Kenia Padrón

kenia.padron@infomed.sld.cu

1 Nuclear Medicine Department, Institute of Cardiology, 17 No. 702, Vedado CP 10 400, La Habana, Cuba
} 